\title{
FUNÇÃO SOCIOAMBIENTAL DE PRAÇAS PÚBLICAS DE ARACAJU-SE
}

\author{
Emanuela Carla Santos ${ }^{1}$, Carla Zoaid Alves dos Santos ${ }^{2}$, Laura Jane Gomes ${ }^{3}$
}

\section{RESUMO}

O objetivo deste estudo foi analisar parâmetros de qualidade nas principais praças públicas na cidade de Aracaju e assim verificar se estas estão cumprindo a sua função socioambiental. Foram avaliados por meio de uma matriz de qualidade ambiental, parâmetros físicos, culturais e ambientais e aplicadas entrevistas semiestruturadas com zeladores e garis quando presentes. Os dados foram sistematizados em planilha Excel e apresentados em porcentagem. As praças avaliadas cumprem com sua função socioambiental de alguma forma, porém, ações como a manutenção frequente e a sensibilização dos usuários são importantes para que as praças cumpram o seu papel.

Palavras-chave: Planejamento urbano; Áreas verdes; Qualidade de vida; Lazer; Recreação.

\section{THE SOCIOENVIRONMENTAL ROLE OF PUBLIC SQUARES IN ARACAJU-SE}

\section{ABSTRACT}

The objective of this study was to analyze quality parameters in the main public squares in the city of Aracaju and so verify that they are fulfilling their environmental function. Were evaluated by an array of environmental quality, physical, cultural and environmental parameters and applied semi-structured interviews with custodians and sweepers when present. The data were summarized in an Excel spreadsheet and presented in percentage.

Recebido em 12.09.2012 e aceito em 27.02.2015

1 Engenheira Florestal (UFS), Mestranda em Desenvolvimento e Meio Ambiente (PRODEMA/UFS). E-mail: manu.karla@hotmail.com

2 Engenheira Florestal, Mestre em Desenvolvimento e Meio Ambiente (PRODEMA/UFS). E-mail: carlazoaid@gmail.com

3 Professora do Departamento de Ciências Florestais da Universidade Federal de Sergipe (DCF/UFS). E-mail: laurabuturi@gmail.com 
The evaluated squares meet their environmental function somehow, but actions like frequent maintenance and awareness of users are important for the squares fulfill their role fully.

Keywords: Urban planning; Green space; Quality of life; Leisure; Recreation.

\section{INTRODUÇÃO}

$\mathrm{Na}$ época do Brasil Colonial, as praças eram destinadas à realização de procissões, comércio informal, encontros e passagem, atividades políticas e militares. Como nestes locais havia maior concentração da população, os administradores da época davam mais atenção e focalização urbanística a estes locais, reunindo ao seu redor a arquitetura de maior apuro (DE ANGELIS et al., 2004).

Os conceitos de praça foram se modificando ao longo dos séculos e até a necessidade de áreas verdes urbanas foi vista de forma diferente a cada época. Nas primeiras décadas do século XIX, discutiam-se os benefícios da arborização nas cidades, graças à mudança de conceito de salubridade urbana. Na segunda metade deste século, a salubridade indicava o estado do meio, das coisas e dos seus elementos constitutivos (SEGAWA, 2005).

Com a crescente urbanização das cidades, as praças tornaram-se as principais áreas de lazer urbano, tornando-se espaços próprios para o uso coletivo, diferentemente do que ocorria no século XIX. Na primeira metade do século $X X$, mais especificamente na década de 1940, com a introdução da prática de esportes, houve a inclusão do lazer esportivo e recreativo nas áreas de praças. Assim, perde-se o caráter de passeio público, com eixos e alamedas mais largos, e um novo padrão é construído, com estares e espaços articulados e entrelaçados, objetivando, ao mesmo tempo, o passeio e as atividades de lazer, com quadras, "playgrounds", anfiteatros, comércio e outros recursos. Este modelo permanece até hoje em boa parte das praças brasileiras (MONTELLI, 2008).

As praças também podem ser classificadas como uma categoria de área verde, quando cumprem a função de espaço público acessível com predomínio de vegetação arbórea, e destinam-se, principalmente ao convívio e ao lazer da população (LIMA et al. 1994; BARGOS; MATIAS, 2011). Essa função está diretamente relacionada com a melhoria da qualidade de vida da população e teoricamente, oferecem para pessoas de todas as idades e classes sociais um espaço para contemplação da natureza, além de recreação, lazer e uma vida mais saudável. 
O fato é que, independente da época, as praças desempenharam e ainda desempenham um papel fundamental na estrutura das cidades: papel ecológico através da manutenção de processos reguladores da qualidade do ambiente; social ao proporcionar lazer, recreação e espaço para interações comunitárias; estético representando objetos referenciais e cênicos que modificam a paisagem urbana; e psicológico por proporcionar sensação de relaxamento aos visitantes (JESUS; BRAGA, 2005; SILVA, 2010).

No entanto, conforme Rolnik (1998), esse tipo de espaço público tem se tornado cada vez mais subutilizado, resumindo-se a espaços para circulação, quando na verdade deveriam ser de permanência. Dessa forma, outras áreas destinadas ao lazer, só que de caráter privado, como "shopping centers", parques, entre outros, estão se tornando os principais espaços de lazer de uma cidade.

Assim, a praça pública, como local da convivência em comunidade no cotidiano de uma cidade, deve ser priorizada dentro do planejamento urbano para que assuma de fato o seu papel de área verde e consequentemente seja alcançada a sua função socioambiental.

Dentro desse contexto, a realização desse trabalho teve como objetivo analisar parâmetros de qualidade nas principais praças públicas na cidade de Aracaju e assim verificar se estas estão cumprindo a sua função socioambiental.

\section{MATERIAIS E MÉTODOS}

A pesquisa foi realizada na cidade de Aracaju, capital de Sergipe, que se situa na região litorânea do estado, ocupa uma área de $182 \mathrm{~km}^{2}$ e atualmente conta com uma população de 552.365 mil habitantes (IBGE, 2010). Fundada em 17 de março de 1855 e construída para ser a sede do Governo do Estado, foi uma das primeiras cidades brasileiras planejadas e edificada sob um projeto que traçou todas as ruas em linha reta, formando quarteirões simétricos que lembravam um tabuleiro de xadrez, a partir da Praça Fausto Cardoso (ARACAJU, 2011a). Este tipo de traçado ainda pode ser notado nos bairros da região central da Capital, como Centro, Cirurgia, Getúlio Vargas, Salgado Filho e São José e nas primeiras praças: Praça Camerino, Praça Olímpio Campos, Praça General Valadão e Praça Tobias Barreto.

Conforme a cidade se desenvolvia, outros bairros, distantes do "Tabuleiro de Pirro" (como ficou conhecida a forma de planejamento adotada na cidade), foram surgindo, com conformações de ruas diferentes e as praças que foram surgindo também seguiam outros padrões e possuíam funcionalidades diferentes (ARACAJU, 2011a). Para este estudo, foram 
avaliadas as 21 principais e maiores praças de Aracaju (Tabela 1), baseando-se nos critérios utilizados no trabalho de Souza et al. (2011), que as considerou como principais por serem as mais citadas e lembradas pela população de Aracaju. Foi verificado também o ano da última intervenção nestas praças, seja construção (no caso das mais recentes) ou reforma total (Tabela 1).

Tabela 1. Praças avaliadas com nome, última reforma realizada (ano), área $\left(\mathrm{m}^{2}\right) \mathrm{e}$ localização, Aracaju, SE

Table 1. Squares which were analyzed with their name, year of most recent remodeling, area (measured in square kilometers) and location, Aracaju, State of Sergipe

\begin{tabular}{ccccc}
\hline Número & Praça & Reforma (Ano) & Área $\mathbf{( m}^{\mathbf{2}}$ ) & Bairro \\
\hline 1 & Olímpio Campos & 1989 & $25.835,53$ & Centro \\
2 & José Atanásio do Nascimento & 1991 & $2.697,63$ & Jabotiana \\
3 & Almirante Tamandaré & 1995 & 452,039 & Centro \\
4 & Bandeira & 1995 & $12.415,11$ & Centro \\
5 & Assis Chateaubriand & 1995 & 907,45 & Salgado Filho \\
6 & Princesa Isabel & 1995 & $5.088,00$ & Santo Antônio \\
7 & Graccho Cardoso & 1995 & 1.562 & São José \\
8 & Imprensa & 1996 & $2.896,59$ & 13 de Julho \\
9 & Poeta Clodoaldo de Alencar & 1996 & $6.398,62$ & Grageru \\
10 & Monteiro Lobato & 1996 & $10.110,97$ & Inácio Barbosa \\
11 & Tobias Barreto & 1996 & 13.019 & São José \\
12 & General Valadão & 1999 & $3.905,14$ & Centro \\
13 & Theodorico do Prado Montes & 2000 & $4.150,69$ & Farolândia \\
14 & Luciano Barreto Júnior & 2003 & $4.606,44$ & Jardins \\
15 & Oliveira Belo & 2004 & $5.863,25$ & Grageru \\
16 & Siqueira de Menezes & 2004 & $1.435,86$ & Santo Antonio \\
17 & Dom José Thomaz & 2004 & $11.991,62$ & Siqueira Campos \\
18 & Camerino & 2007 & $9.242,32$ & Centro \\
19 & Getúlio Vargas & 2008 & 1.737 & São José \\
20 & Fausto Cardoso & 2009 & $10.504,09$ & Centro \\
21 & Almirante Barroso & 2010 & $5.783,38$ & Centro \\
\hline
\end{tabular}

A análise das principais praças de Aracaju/SE foi realizada por meio de uma avaliação qualitativa e quantitativa in loco de aspectos físico-estruturais, socioculturais e ambientais de cada unidade de estudo (praça) e realização de entrevistas semiestruturadas com zeladores quando presentes no local. As definições e parâmetros utilizados foram estruturados conforme metodologia, adaptada de Silva Filho et al., (2002) e De Angelis et al., (2004), os quais foram avaliados da seguinte forma:

a) Aspectos físicos: corresponderam aos elementos de infraestrutura e equipamentos presentes ou ausentes na praça: quantidade de bancos sombreados (\%) pela copa das árvores, avaliados durante o dia e estado de conservação destes. O estado de conservação dos bancos foi avaliado sob a ótica de três aspectos: ocorrência de pichações, vandalismo e a ação natural de intemperismo e a qualificação deste estado foi avaliada de acordo com a seguinte escala: Ótimo: entre $75 \%$ a $100 \%$ dos bancos apresentam condições 
de uso; Bom: entre 50\% e 74\% dos bancos apresentam condições de uso; Regular: entre 25 e $49 \%$ dos bancos da praça apresentam condições de uso; Ruim: menos de $24 \%$ dos bancos apresentam condições de uso.

Foi realizada também a contagem de lixeiras e observação quanto à funcionalidade (seletivas ou não) e verificou-se a presença de equipamento de lazer, quanto a sua funcionalidade e tipo (quadra de esportes, campo; estrutura para a terceira idade e parque infantil).

A acessibilidade também foi avaliada e neste estudo foi definida como a facilidade de qualquer indivíduo ou grupo de se alcançar fisicamente os destinos desejados, considerando ainda os elementos que facilitam ou não esse acesso (BRASIL, 2005; MACHADO; WAISMAN, 2011). Dessa forma, procurou-se determinar como as praças atendem tais critérios observando a existência de elementos como estacionamentos; pontos de ônibus; ciclovias e bicicletários; Sinalização Horizontal (trânsito: faixas indicativas de estacionamento; de redução de velocidade; e de pedestres); Sinalização Vertical (placas informativas usuais e em braile); Rampas para cadeirantes (estado de conservação e distribuição); piso tátil (observou-se a existência de indicação do final do perímetro da praça e a forma de distribuição); e por fim observou-se a ocorrência de obstáculos físicos que dificultam o livre trânsito de pessoas, como postes, buracos, dentre outros.

b) Aspectos socioculturais: corresponderam aos elementos que proporcionam a realização de eventos (feiras, shows e outros) e que preservam as características culturais e históricas do local, classificados como Coretos (espécie de palanque ou coro, construído ao ar livre, para concertos musicais); Anfiteatro (arquibancadas dispostas circularmente para aulas ou espetáculos); espaços para feiras culturais ou livres; Palcos; Bustos: escultura de cabeça humana, com o pescoço e parte do peito; Estátuas (figura inteira, esculpida ou moldada em uma substância sólida, geralmente representando um homem, um animal ou uma divindade); e Monumentos (demais elementos arquitetônicos que não se encaixam no conceito de bustos ou estátuas, tais como quadros e esculturas). Foi observado também o estado de conservação; registrando atos de vandalismo e a ação do intemperismo, registrados por fotografias.

c) Aspectos ambientais: foram analisados elementos que contribuem para uma melhor qualidade microclimática do local: (1) Presença de espelhos d'água, chafariz ou lagoas; (2) Tipo de pavimentação mais adequado ao conforto ambiental, comparando-se o tipo de pavimento existente nas praças com os valores analisados por Mascaró e Mascaró (2009). Os autores identificaram a taxa de albedo e do índice de refletância de diversos 
materiais e superfícies urbanas típicas, tais como pedra portuguesa, paralelepípedo, concreto, areia e outros.

Todas as informações coletadas foram sistematizadas no programa Microsoft Excel e os resultados tanto qualitativos como quantitativos foram organizados em tabelas e discutidos em porcentagens.

\section{RESULTADOS E DISCUSSÃO}

\section{Qualidade dos aspectos físicos}

a) Bancos

A qualidade da estrutura física das praças apresenta-se como um aspecto fundamental para a permanência das pessoas nesses locais. Os bancos apresentaram-se como um dos principais equipamentos e em todas as praças avaliadas esse elemento está presente, com exceção da Praça Tobias Barreto, onde as pessoas utilizam o batente dos canteiros como assentos. Observou-se também que em $62 \%$ das praças os bancos avaliados apresentam-se conservados e adequados para o uso com um estado de conservação ótimo ou bom, representando assim um aspecto positivo da análise e apenas em $28,5 \%$ das praças os bancos precisam de manutenção e alguns de substituição caracterizados por um estado regular ou péssimo (Tabela 2).

Outro aspecto importante na análise do uso dos bancos é o seu sombreamento pela copa das árvores, o qual se apresenta como um fator preponderante para a permanência das pessoas por mais tempo na praça por oferecer melhor conforto térmico aos visitantes durante o período diurno. Em $85 \%$ das praças pesquisadas cerca de $50 \%$ dos bancos estão instalados sob a sombra de árvores. Somente as Praças Camerino e Poeta Clodoaldo apresentaram $100 \%$ dos bancos sombreados.

Nas praças que apresentaram um baixo percentual de bancos sombreados observou-se que as árvores foram plantadas distantes dos bancos (ou vice-versa), fato que demonstra a necessidade de uma melhor distribuição espacial dos bancos das praças, devendo-se dispensar o cuidado de observar como o conforto térmico do espaço será oferecido ao usuário, ressaltando que as árvores são um dos elementos responsáveis por essa sensação de conforto.

$\mathrm{Na}$ Praça Luciano Barreto Júnior, esse fato chama mais a atenção por ser uma praça recente (construída em 2001) e percebe-se que o sombreamento dos bancos é oferecido 
quase que por acaso dentro do desenho arquitetônico da praça. Essa constatação comprova que não se pensou nesse aspecto durante a realização do projeto das praças. $A$ fase de implantação também deve ser acompanhada de forma técnica a fim de garantir a observância desse item.

Tabela 2. Presença, porcentagem de sombreamento e estado de conservação dos bancos das praças de Aracaju, SE

Table 2. Presence, percentage of shade and state of conservation of the squares' bench of Aracaju, State of Sergipe

\begin{tabular}{lccc}
\hline Praça & Presença & Sombreados (\%) & Conservação \\
\hline Almirante Barroso & Sim & 61,3 & Bom \\
Almirante Tamandaré & Sim & 66,7 & Ótimo \\
Assis Chateaubriand & Sim & 50 & Ótimo \\
Bandeira & Sim & 95,3 & Bom \\
Camerino & Sim & 100 & Regular \\
Dom José Thomaz & Sim & 75 & Regular \\
Fausto Cardoso & Sim & 51,7 & Ótimo \\
General Valadão & Sim & 0 & Bom \\
Getúlio Vargas & Sim & 52,2 & Ótimo \\
Graccho Cardoso & Sim & 55,6 & Regular \\
Imprensa & Sim & 70,0 & Bom \\
José Atanásio do Nascimento & Sim & 75 & Bom \\
Luciano Barreto Júnior & Sim & 33,3 & Ótimo \\
Monteiro Lobato & Sim & 16,7 & Regular \\
Olímpio Campos & Sim & 93,75 & Péssimo \\
Oliveira Belo & Sim & 33,3 & Bom \\
Poeta Clodoaldo de Alencar & Sim & 100 & Ótimo \\
Princesa Isabel & Sim & 50 & Péssimo \\
Siqueira de Menezes & Sim & 48 & Ótimo \\
Theodorico do P. Montes & Sim & 76,9 & Bom \\
Tobias Barreto & Não & 0 & - \\
\hline & & Fonte: Dados da pesquisa
\end{tabular}

b) Lixeiras

Em relação às Lixeiras, observou-se que este equipamento não está presente em todas as praças analisadas. Em $28,5 \%$ das praças visitadas não existem coletores de lixo. Nas praças com pontos comerciais, a única opção para a coleta de lixo está disponível junto aos coletores dos quiosques, lanchonetes e demais pontos de comércio (geralmente barris). Não há uma uniformidade nos tipos de coletores presentes e nem uma distribuição satisfatória, a qual seria ideal a presença desse equipamento em todos os pontos laterais.

Apenas em 19 das praças há presença de coletores seletivos, porém esse serviço não é realizado de fato (Tabela 3). O que ocorre, na prática, é a ação de catadores autônomos, não registrados por nenhuma associação ou cooperativa, que trabalham principalmente com a coleta de metais, que possuem maior preço. De acordo com as informações de garis e zeladores entrevistados, ocorre apenas a coleta convencional, em 
que todo o lixo recolhido nas praças públicas tem o mesmo destino de grande parte dos resíduos de Aracaju. A freqüência de coleta ocorre no final da tarde, de segunda a sextafeira. Não basta ter coletores seletivos se o município não implanta um Sistema de Coleta Seletiva, conforme previsto na Política Nacional de Resíduos Sólidos (BRASIL, 2011), transformando as praças, por exemplo em Ecopontos, que são locais como referência para a Coleta Seletiva, em conjunto com ações de educação ambiental.

Tabela 3. Quantidade, tipo e forma de coleta de lixo das praças de Aracaju, SE

Table 3. Quantity, type and way of garbage collection of the squares' bench of Aracaju, State of Sergipe

\begin{tabular}{lcclc}
\hline Praça & Quantidade & $\begin{array}{c}\text { Seletivas } \\
(\%)\end{array}$ & Tipo de coleta & Lixeiras $/ \mathrm{m}^{2}$ \\
\hline Almirante Barroso & 7 & $0 \%$ & Convencional & 0,00058 \\
Almirante Tamandaré & 0 (Ausente) & $0 \%$ & Convencional & 0 \\
Assis Chateaubriand & 0 (Ausente) & $0 \%$ & Convencional & 0 \\
Bandeira & 9 & $0 \%$ & Convencional & 0,00035 \\
Camerino & 3 & $66 \%$ & Convencional & 0,00028 \\
Dom José Thomaz & 2 & $100 \%$ & Convencional & $6,62132^{*} 10^{-5}$ \\
Fausto Cardoso & 5 & $100 \%$ & Convencional & 0,00042 \\
General Valadão & 1 & $100 \%$ & Convencional & 0,00025 \\
Getúlio Vargas & 3 & $0 \%$ & Convencional & 0,0005 \\
Graccho Cardoso & 1 & $0 \%$ & Convencional & 0,00046 \\
Imprensa & 4 & $0 \%$ & Convencional & 0,00115 \\
José A. do Nascimento & 0 (Ausente) & $0 \%$ & Convencional & 0 \\
Luciano Barreto Júnior & 8 & $0 \%$ & Convencional & 0,00172 \\
Monteiro Lobato & 0 (Ausente) & $0 \%$ & Convencional & 0 \\
Olímpio Campos & 5 & $0 \%$ & Convencional & 0,00035 \\
Oliveira Belo & (2 barris e 3 & $0 \%$ & Convencional & 0,00082 \\
& coletores) & & & \\
Poeta C. de Alencar & 0 (Ausente) & $0 \%$ & Convencional & 0 \\
Princesa Isabel & 0 (Ausente) & $0 \%$ & Convencional & 0 \\
Siqueira de Menezes & 7 & $0 \%$ & Convencional & 0,00365 \\
Theodorico do P. Montes & 2 & $0 \%$ & Convencional & 0,00044 \\
Tobias Barreto & 6 & $0 \%$ & Convencional & 0,00042 \\
\hline
\end{tabular}
Fonte: Dados da pesquisa

c) Equipamentos de lazer

Os equipamentos de lazer são mais recentes no histórico das praças. De acordo com Robba e Macedo (2003), foi a partir de 1940 que as praças começaram a contar com equipamentos como quadras para prática esportiva e brinquedos para recreação infantil, mesas de jogos e outros, inspiração de arquitetos como Roberto Burle Marx, Thomas Church e Garret Eckbo. 
Em 38,1\% das praças não há nenhum tipo de equipamento para o lazer ou recreação. Porém, foi encontrado pelo menos um equipamento de lazer em $62 \%$ das praças avaliadas (Tabela 4).

O estado de conservação desses equipamentos ainda não é satisfatório, principalmente os parques infantis que apresentam um estado de conservação de regular a péssimo. Apenas os equipamentos de lazer das Praças Luciano Barreto Júnior e Bandeira estão em boas condições de uso.

Segundo Souza (2009), no Brasil, não se tem o hábito de realizar investigações que avaliem a performance dos ambientes construídos após um tempo de uso, seja em ambientes residenciais, comerciais ou de lazer, dessa forma isto ocasiona a repetição de erros, a não identificação dos acertos e principalmente a não previsão de problemas.

Tabela 4. Equipamentos de Lazer encontrados em 21 praças visitadas de Aracaju, SE Table 4. Leisure equipment found in 21 squares of Aracaju, State of Sergipe

\begin{tabular}{|c|c|c|}
\hline Praça & Equipamentos de lazer & Conservação \\
\hline Almirante Barroso & Estrutura $3^{\mathrm{a}}$ idade & Ótimo \\
\hline Almirante Tamandaré & Não & Ausente \\
\hline Assis Chateaubriand & Parque infantil & Péssimo \\
\hline Bandeira & Parque infantil & Regular \\
\hline Camerino & Não & Ausente \\
\hline Dom José Thomaz & Quadra, Estrutura $3^{a}$ idade, Parque infantil & Bom \\
\hline Fausto Cardoso & Estrutura $3^{a}$ idade & Ótimo \\
\hline General Valadão & Não & Ausente \\
\hline Getúlio Vargas & Não & Ausente \\
\hline Graccho Cardoso & Não & Ausente \\
\hline Imprensa & Quadra & Bom \\
\hline José A. do Nascimento & Não & Ausente \\
\hline Luciano Barreto Júnior & Eq. para exercícios físicos, parque infantil & Ótima \\
\hline Monteiro Lobato & Quadra, "Campo" e Mesas para jogos & Péssimo \\
\hline Olímpio Campos & Não & Ausente \\
\hline Oliveira Belo & Quadra e aparelhos de ginástica & Bom \\
\hline Poeta Clodoaldo de Alencar & Quadra & Bom \\
\hline Princesa Isabel & Não & Ausente \\
\hline Siqueira de Menezes & Outros & Ótimo \\
\hline Theodorico do P. Montes & Campo & Não é utilizado \\
\hline Tobias Barreto & Parque Infantil & Regular \\
\hline
\end{tabular}

Fonte: Dados da pesquisa

d) Acessibilidade e mobilidade

As praças pesquisadas contam com alguma forma de sinalização horizontal (Tabela 5). Cerca de $30 \%$ das praças não contam com qualquer tipo de sinalização, seja pintura no chão ou faixa de pedestres. Distribuição irregular e faixas com pinturas gastas estão entre os principais problemas encontrados na sinalização horizontal das praças avaliadas. Apenas $20 \%$ das praças contam com faixas de pedestres (principal forma de sinalização horizontal) 
em ótimo estado de conservação. Além disso, apenas nas praças com reformas recentes são encontradas faixas em todos os lados da praça, como é o caso da Praça Almirante Barroso (2010), Praça Fausto Cardoso (2009) e Praça Luciano Barreto Júnior (2003).

Tabela 5. Presença, tipo e estado de conservação da sinalização horizontal das praças de Aracaju, SE

Tabel 5. Presence, type and state of conservation of the squares' markings of Aracaju, State of Sergipe

\begin{tabular}{lccc}
\hline Praça & Presença & Tipo & Conservação \\
\hline Almirante Barroso & Sim & Faixa de Pedestre & Bom \\
Almirante Tamandaré & Não & - & - \\
Assis Chateaubriand & Não & - & - \\
Bandeira & Sim & Faixa de Pedestre & Ótimo \\
Camerino & Sim & Faixa de Pedestre & Ótimo \\
Dom José Thomaz & Sim & Faixa de Pedestre & Bom \\
Fausto Cardoso & Sim & Faixa de Pedestre & Ótimo \\
General Valadão & Sim & Faixa de Pedestre & Ótimo \\
Getúlio Vargas & Sim & Faixa de Pedestre & Ótimo \\
Graccho Cardoso & Sim & Faixa de Pedestre & Bom \\
Imprensa & Sim & Faixa de Pedestre & Bom \\
José A. do Nascimento & Sim & Faixa de Pedestre & Regular \\
Luciano Barreto Júnior & Sim & Faixa de Pedestre & Bom \\
Monteiro Lobato & Não & - & - \\
Olímpio Campos & Sim & Faixa de Pedestre & Bom \\
Oliveira Belo & Não & - & - \\
Poeta Clodoaldo de Alencar & Não & - & - \\
Princesa Isabel & Não & - & - \\
Siqueira Menezes & Sim & Faixa de Pedestre & Bom \\
Theodorico do P. Montes & Não & - & - \\
Tobias Barreto & Sim & Faixa de Pedestre & Bom \\
\hline & & \multicolumn{1}{c}{ Fonte: Dados da pesquisa }
\end{tabular}

Os problemas com sinalização vertical também ocorrem nas mesmas praças que não possuem sinalização horizontal, como é o caso da Praça Assis Chateaubriand, Praça Monteiro Lobato, Praça Poeta Clodoaldo de Alencar e Praça Theodorico do Prado Montes (Tabela 6), todas com reformas realizadas entre os anos 1995 e 2000. Além das praças citadas, a Praça José Atanásio do Nascimento não possui qualquer tipo de placa ou informativo.

Quanto ao estado de conservação, observou-se mais uma vez a importância da manutenção frequente destes espaços, especialmente nas que são importantes pontos de 
referência da cidade. Quase todas as placas estão em ótimo estado de conservação, devido à implantação recente. Na Praça Getúlio Vargas, os informativos com a história da cidade são um atrativo para frequentadores; na Praça Siqueira de Menezes, localizada na Colina Santo Antônio, marco zero de Aracaju, há a transcrição do decreto de criação de Aracaju. A importância das placas informativas não está somente quanto à questão da localização e identificação, mas também como caracterização do espaço da praça.

Tabela 6. Presença, tipo e estado de conservação da sinalização vertical das praças de Aracaju, SE

Tabel 6. Presence, type and state of conservation of the squares' vertical markings of Aracaju, State of Sergipe

\begin{tabular}{lcccc}
\hline Praça & Presença & Placas & Informativos & Conservação \\
\hline Almirante Barroso & Sim & 2 & 0 & Ótimo \\
Almirante Tamandaré & Sim & 2 & 0 & Ótimo \\
Assis Chateaubriand & Ausente & - & - & - \\
Bandeira & Sim & 1 & 0 & Ótimo \\
Camerino & Sim & 1 & 0 & Ótimo \\
Dom José Thomaz & Sim & 2 & 0 & Ótimo \\
Fausto Cardoso & Sim & 4 & 0 & Bom \\
General Valadão & Sim & 3 & 0 & Bom \\
Getúlio Vargas & Sim & 1 & Fotos antigas & Ótimo \\
Graccho Cardoso & Sim & 1 & 0 & Ótimo \\
Imprensa & Sim & 1 & 0 & Bom \\
José A. do Nascimento & Ausente & - & - & - \\
Luciano Barreto Júnior & Sim & 2 & Memorial & Ótimo \\
Monteiro Lobato & Ausente & - & - & - \\
Olímpio Campos & Sim & 4 & 0 & Bom \\
Oliveira Belo & Sim & 4 & 0 & Regular \\
Poeta Clodoaldo de Alencar & Ausente & - & - & - \\
Princesa Isabel & Sim & 2 & 0 & Bom \\
Siqueira de Menezes & Sim & 2 & Dec. de criação Aracaju & Bom \\
Theodorico do P. Montes & Ausente & - & - & Bom \\
Tobias Barreto & Sim & 5 & 0 & Fonte: Dados da pesquisa
\end{tabular}

Nenhuma praça possui sinalização em braile e apenas três praças possuem piso tátil: Praça Getúlio Vargas, Praça Fausto Cardoso e Praça Almirante Barroso (Tabela 7). Os pisos táteis destas praças estão em ótimo estado de conservação, em volta da praça e não possuem obstáculos. Estas praças passaram por reformas entre os anos de 2008 a 2010, revelando a necessidade de implantar estes equipamentos nas outras praças, sejam antigas 
ou novas. Quanto às rampas, foi observado que apenas na Praça José Atanásio do Nascimento estas não estão presentes. Porém, existe uma má distribuição (nem sempre há rampas em todos os lados da praça); falta de piso adequado e de sinalização; além disso, obstáculos como barreiras físicas e veículos estacionados tornam as rampas pouco funcionais na maior parte das praças pesquisadas. Apenas na Praça Fausto Cardoso e na Praça Almirante Barroso as rampas estão em situação adequada: em todos os lados, bem conservadas e sinalizadas.

Convém ressaltar que existe normatização específica para que a acessibilidade seja alcançada no espaço público. Trata-se da NBR 9050 criada em 2004 e estabelece critérios e parâmetros técnicos a serem observados quando do projeto, construção, instalação e adaptação de edificações, mobiliário, espaços e equipamentos urbanos às condições de acessibilidade (ABNT, 2004). Diante dos resultados analisados nesta pesquisa, ao que tudo indica alguns critérios relacionados a essa normatização estão sendo adotadas de forma gradativa pela prefeitura de Aracaju na medida as praças estão passando por reformas.

Tabela 7. Presença, quantidade e distribuição espacial das rampas das praças de Aracaju, SE

Tabel 7. Presence, quantity and spacial distribution of squares' ramp of Aracaju, State of Sergipe

\begin{tabular}{|c|c|c|c|}
\hline Praça & Presença & Quantidade & Distribuição espacial \\
\hline Almirante Barroso & Sim & 1 & Em apenas um lado \\
\hline Almirante Tamandaré & Sim & 5 & Em todos os lados \\
\hline Assis Chateaubriand & Sim & 5 & Em todos os lados \\
\hline Bandeira & Sim & 9 & Em todos os lados da praça \\
\hline Camerino & Sim & 7 & Em todos os lados da praça. \\
\hline Dom José Thomaz & Sim & 6 & Em todos os lados da praça. \\
\hline Fausto Cardoso & Sim & 7 & Em todos os lados da praça. \\
\hline General Valadão & Sim & 2 & Em apenas dois lados da praça. \\
\hline Getúlio Vargas & Sim & 3 & Em todos os lados da praça. \\
\hline Graccho Cardoso & Sim & 6 & Em todos os lados da praça. \\
\hline Imprensa & Sim & 3 & Em apenas dois lados da praça. \\
\hline José A. do Nascimento & Não & - & - \\
\hline Luciano Barreto Júnior & Sim & 5 & Em todos os lados da praça. \\
\hline Monteiro Lobato & Sim & 6 & Em todos os lados da praça. \\
\hline Olímpio Campos & Sim & 9 & Em todos os lados da praça. \\
\hline Oliveira Belo & Sim & 5 & Em todos os lados da praça. \\
\hline Poeta Clod. de Alencar & Sim & 3 & Sem sinalização \\
\hline Princesa Isabel & Sim & 7 & Em todos os lados da praça. \\
\hline Siqueira de Menezes & Sim & 3 & Em três lados da praça. \\
\hline Theodorico do P. Montes & Sim & 2 & Em apenas dois lados da praça. \\
\hline Tobias Barreto & Sim & 8 & Em todos os lados da praça \\
\hline
\end{tabular}

Fonte: Dados da pesquisa. 


\section{Aspectos socioculturais das praças}

a) Eventos culturais

Em $66 \%$ das vinte e uma praças visitadas não há nenhum tipo de espaço dedicado a eventos e em apenas três praças ocorrem eventos culturais (Tabela 8). Na Praça Fausto Cardoso, ocorre apresentações teatrais, manifestações de caráter artístico e político principalmente por estar localizada em frente à Assembléia Legislativa do município; na Praça Olímpio Campos, existe uma feira cultural de segunda a sábado e na Praça Tobias Barreto, mesmo sem um espaço apropriado, ocorre o Projeto Freguesia, onde aos domingos ocorrem apresentações de bandas locais e uma feira cultural (ARACAJU, 2011b). Apenas na Praça Oliveira Belo ocorre feira livre de produtos alimentícios.

Alguns aspectos negativos foram observados os quais podem ser gerenciados por meio de planos de gestão que apresentem estratégias e metas especificas para solucionar os problemas existentes. Por exemplo, na Praça da Bandeira, existe o Memorial da Bandeira que conserva aspectos da história da Bandeira Nacional, porém, não há informações sobre horários de funcionamento deste espaço e nem ações de divulgação. Os coretos das praças Almirante Barroso, Bandeira e Fausto Cardoso são utilizados como "banheiros" por moradores de rua, e depósito de lixo inviabilizando a utilização destes espaços.

A manutenção dessas estruturas principalmente quanto à limpeza e/ou reformas, deve ser priorizada no gerenciamento, porque além de serem elementos que servem para o desenvolvimento de atividades culturais/e ou artísticas, são essenciais para a manutenção da estética do local.

A Praça Tobias Barreto possui um anfiteatro que é utilizado como banco; e o anfiteatro da Praça Camerino, por estar em um espaço não sombreado e pela ausência de eventos, não é utilizado para função a qual foi construído. 
Tabela 8. Presença e tipo de espaço para a ocorrência de eventos artísticos de 21 praças de Aracaju, SE

Table 8. Presence and type of space for the occurrence of artistic events of 21 squares in Aracaju, State of Sergipe

\begin{tabular}{lcc}
\hline Praça & Presença e tipo & Tipo de evento \\
\hline Almirante Barroso & 1 Coreto & Nenhum \\
Almirante Tamandaré & Ausente & Nenhum \\
Assis Chateaubriand & Ausente & Nenhum \\
Bandeira & 1 Coreto e Memorial da Bandeira & Nenhum \\
Camerino & 1 Palco e 1 Anfiteatro & Nenhum \\
Dom José Thomaz & Ausente & Apresentações teatrais \\
Fausto Cardoso & 2 coretos & Nenhum \\
General Valadão & Ausente & Nenhum \\
Getúlio Vargas & Ausente & Nenhum \\
Graccho Cardoso & Ausente & Nenhum \\
Imprensa & Ausente & Nenhum \\
José A. do Nascimento & Ausente & Nenhum \\
Luciano Barreto Júnior & Ausente & Feira cultural \\
Monteiro Lobato & Ausente & Feira livre aos sábados \\
Olímpio Campos & Espaços para feiras & Nenhum \\
Oliveira Belo & Ausente & Nenhum \\
Poeta Clod. de Alencar & Ausente & Nenhum \\
Princesa Isabel & Ausente & Nenhum \\
Siqueira de Menezes & Ausente & Projeto Freguesia \\
Theodorico do P. Montes & Ausente & Fonte: dados dapesquisa \\
Tobias Barreto & 1 Anfiteatro & \\
\hline
\end{tabular}

Fonte: dados da pesquisa

b) Monumentos históricos

Juntamente com os espaços para eventos artísticos, os monumentos históricos contribuem para a caracterização das praças. Além disso, remetem a momentos históricos ou a personalidades importantes, permitindo que os seus frequentadores conheçam um pouco mais da história do local ao qual pertencem.

Observou-se que em $66,6 \%$ das praças avaliadas existe algum tipo de monumento, com destaque aos mais significativos por remetem a fatos marcantes da história do Estado de Sergipe, a exemplo do Busto da Praça Fausto Cardoso que representa seu patrono, registra o duelo histórico entre os grupos políticos de Olímpio Campos e Fausto Cardoso, no início do século XX (PRADO, 2009). As Praças Camerino (Silvio Romero) e Tobias Barreto recordam duas importantes personalidades do Estado, respectivamente, crítico literário e poeta do final do século XIX (MOTA, 2000). Esses monumentos são cartões postais dessas praças.

Por outro lado, em $33,3 \%$ das praças não existe qualquer monumento que referencie o nome da praça ou fato que relembre a homenagem ou motivo pelo qual a praça leva o 
referido nome (Tabela 9). Tal fato constitui-se em um aspecto negativo, pois a presença de monumentos é importante para que a população possa lembrar quem é a pessoa ou fato homenageado pela praça e a sua importância dentro contexto histórico, além de contribuir para o embelezamento da praça. Convém ressaltar que neste estudo, as praças Assis Chateaubriand, Oliveira Belo e Princesa Isabel, durante a avaliação "in loco" somente foram identificadas devido às placas utilizadas para identificar o nome dos logradouros. Praças que possuem monumentos são mais facilmente identificáveis e apresentam uma melhor significação histórica, desde que esses elementos estejam devidamente identificados.

Tabela 9. Tipo e conservação dos monumentos históricos encontrados nas 21 praças estudadas de Aracaju, SE

Table 9. Type and conservation of historical monuments found in 21 squares of Aracaju, State of Sergipe

\begin{tabular}{lcc}
\hline Praça & Tipo & Conservação \\
\hline Almirante Barroso & Monumento & Otimo \\
Almirante Tamandaré & Busto & Falta de limpeza \\
Assis Chateaubriand & Ausente & Ausente \\
Bandeira & Mastros (sem bandeiras) & Intemperismo \\
Camerino & Monumento & Vand., Pich. e Intemp. \\
Dom José Thomaz & Busto & Vand., Pich., Intemp. \\
Fausto Cardoso & Estátuas & Vand., Pich., Sugeira \\
General Valadão & Estátuas & Vand., Pich. e Intemp. \\
Getúlio Vargas & Ótimo \\
Graccho Cardoso & Busto e fotos antigas & Vand., Pich., Intemp. e Sugeira \\
Imprensa & Monumento & Ótimo \\
José A. do Nascimento & 1 monumento & Ausente \\
Luciano Barreto Júnior & Ausente & Intemperismo \\
Monteiro Lobato & Monumento & Ausente \\
Olímpio Campos & Ausente & Intemp. e Vandalismo \\
Oliveira Belo & Estátuas & Ausente \\
Poeta Clodoaldo de Alencar & Ausente & Ausente \\
Princesa Isabel & Ausente & Ausente \\
Siqueira de Menezes & Ausente & Busto \\
Theodorico do P. Montes & Ausente & Vand., Pich., Intemp. e Sugeira \\
Tobias Barreto & Estátuas & Vand., Pich e Intemperismo \\
\hline Legenda: Vand. = Vandalismo; Pich. = Pichação; Intemp. = Intemperismo & Fonte: Dados da pesquisa. \\
& &
\end{tabular}

Quanto ao estado de conservação dos monumentos observou-se que em 52,4\% das praças existe algum tipo de problema quanto a manutenção dos monumentos e em apenas $14,3 \%$ esses elementos apresentam um ótimo estado de conservação.

Constatou-se que o principal problema para manutenção desses monumentos é o vandalismo, lembrando que conforme a Lei de Crimes Ambientais, (BRASIL, 1988), ações que depredam monumentos históricos constituem crime ambiental, com pena de três meses a um ano de detenção e multa. 


\section{Aspectos ambientais}

\section{a) Espelhos d'água}

A existência de fontes d'água (como espelhos d'água, chafarizes e lagoas) contribui, assim como a vegetação, para um melhor conforto térmico e formação de um microclima mais agradável, através do aumento da umidade relativa do local (MASCARÓ e MASCARÓ, 2009). Porém, verificou-se que este tipo de recurso não é comum nas praças de Aracaju/SE e, quando existem, não há uma manutenção adequada servindo para outros fins tais como criadouro de animais e abastecimento de água para a própria praça.

Apenas em $23,8 \%$ das praças visitadas foram encontradas fontes d'água (Tabela 10). Nas praças Olímpio Campos e Tobias Barreto, as fontes são lagos que servem para a criação de animais para a contemplação de visitantes, como alguns tipos de aves. Já nas praças Almirante Barroso e Fausto Cardoso, tais elementos estão presentes para o abastecimento de água da praça.

Tabela 10. Espelhos d'água encontrados em 21 praças de Aracaju, SE

Table 10. Fountain water found in 21 squares of Aracaju, State of Sergipe

\begin{tabular}{lc}
\hline Praça & Espelhos d'água \\
\hline Almirante Barroso & Fontes e bomba d'água \\
Almirante Tamandaré & Não \\
Assis Chateaubriand & Não \\
Bandeira & Não \\
Camerino & Não \\
Dom José Thomaz & Não \\
Fausto Cardoso & 2 Fontes \\
General Valadão & Não \\
Getúlio Vargas & Não \\
Graccho Cardoso & Não \\
Imprensa & Não \\
José Atanásio do Nascimento & Não \\
Luciano Barreto Júnior & Não \\
Monteiro Lobato & Não \\
Olímpio Campos & Lagoas \\
Oliveira Belo & Não \\
Poeta Clodoaldo de Alencar & Não \\
Princesa Isabel & Não \\
Siqueira de Menezes & 1 Fonte \\
Theodorico do P. Montes & Não \\
Tobias Barreto & Lagoas \\
\hline
\end{tabular}

Alguns aspectos negativos foram observados: na Praça Olímpio Campos, os locais próximos às lagoas exalavam um forte mau cheiro, enquanto que na Praça Fausto Cardoso havia água parada próximo às fontes, representando um local para a reprodução do mosquito Aedes aegypti, transmissor da dengue. 
As fontes d'água podem ser pensadas como elementos do conforto térmico dentro dos projetos arquitetônicos das praças, porém a sua implantação requer uma ação de manutenção mais minuciosa e frequente do que as de outros elementos, a fim de evitar a ocorrência de aspectos negativos como os encontrados nas praças avaliadas.

b) Pavimentação

O tipo de pavimentação também é outro elemento que contribui para a manutenção de um microclima mais agradável (MASCARÓ E MASCARÓ, 2009). Nas praças de Aracaju os tipos de pavimentação encontrados foram a pedra portuguesa, o concreto, 0 paralelepípedo e o piso do tipo azulejo (Tabela 11).

Tabela 11. Tipos de pisos de pavimentação e estado de conservação encontrados em 21 praças de Aracaju, SE

Table 11. Types of flooring and paving condition found in 21 squares of Aracaju, State of Sergipe

\begin{tabular}{lcc}
\hline Praça & Tipo & Conservação \\
\hline Almirante Barroso & Pedra portuguesa & Ótimo \\
Almirante Tamandaré & Concreto & Bom \\
Assis Chateaubriand & Concreto & Regular \\
Bandeira & Paralelepípedo e pedra portuguesa & Regular \\
Camerino & Pedra portuguesa & Regular \\
Dom José Thomaz & Paralelepípedo e concreto & Regular \\
Fausto Cardoso & Pedra portuguesa & Ótimo \\
General Valadão & Piso do tipo azulejo & Regular \\
Getúlio Vargas & Pedra portuguesa e concreto & Ótimo \\
Graccho Cardoso & Concreto & Bom \\
Imprensa & Pedra portuguesa e concreto & Bom \\
José A. do Nascimento & Paralelepípedo & Regular \\
Luciano Barreto Júnior & Piso do tipo azulejo & Ótimo \\
Monteiro Lobato & Concreto & Bom \\
Olímpio Campos & Concreto & Regular \\
Oliveira Belo & Concreto & Bom \\
Poeta Clod. de Alencar & Paralelepípedo e pedra portuguesa & Regular \\
Princesa Isabel & Paralelepípedo & Bom \\
Siqueira de Menezes & Paralelepípedo & Bom \\
Theodorico do P. Montes & Paralelepípedo & Regular \\
Tobias Barreto & Concreto & Bom \\
\hline
\end{tabular}

O albedo é a unidade em porcentagem utilizada para indicar quanto da radiação solar recebida por alguma superfície será refletida, assim, quanto maior o albedo do material, maior é a reflexão da radiação solar por esse material consequentemente maior é a sensação térmica de calor (CALVACANTE, 2007). Utilizando como exemplo o concreto, um dos tipos de pavimentação mais encontrados nas praças avaliadas (presente em $33,3 \%$ ), verifica-se que o valor do albedo fica entre 10 e $35 \%$, isso significar dizer, conforme 
Cavalcante (2007), que o concreto reflete de 10 a $35 \%$ da radiação recebida pelo sol. O restante da radiação é o valor de emitância do material, ou seja, o quanto de calor é absorvido pela superfície do material e emitido em forma de onda para o exterior. Considerando os critérios dos autores citados dentre os tipos de pavimentação encontrados nas praças de Aracaju, verifica-se que os pavimentos mais adequados são o concreto e a pedra portuguesa, por apresentarem menor albedo em detrimento dos outros tipos encontrados.

\section{CONCLUSÕES}

Pode-se concluir que as vinte e uma praças analisadas neste estudo cumprem com a sua função socioambiental de forma satisfatória, principalmente por funcionarem como uma área de lazer. Porém, para que as praças analisadas cumpram plenamente com sua função é importante observar alguns aspectos: monitoramento constante das condições dos equipamentos; a implantação de equipamentos de lazer e espaços para eventos nas praças que ainda não os possuem; implantação de coletores seletivos em todas as praças e tornálas referência para a prática da Coleta Seletiva; e ações de Educação Ambiental visando à sensibilização da população quanto à importância destes espaços.

Tais aspectos podem contribuir com a melhoria dos serviços esperados dentro desses espaços para que as praças possam cumprir plenamente seu papel ecológico, psicológico, social e estético.

\section{REFERÊNCIAS}

ARACAJU. Aracaju 154 Anos: História. Disponível em: <http://www.aracaju.se.gov.br/1 54anos/index.php?act=fixa\&materia=historia>. Acesso em: 21 jun. 2011.

ARACAJU. Forró será destaque na programação do Projeto Freguesia. Disponível em: <http://www.aracaju.se.gov.br/index.php?act=leitura\&codigo=45932>. Acesso em: 21 jun. 2011.

ARACAJU. Plano Diretor. Disponível em: < http://www.aracaju.se.gov.br/planejamento/ ?act=fixo\&materia=plano_diretor>. Acesso em: 04 abr. 2011. 
ARACAJU. Programa "Adote o Verde" contribui para a manutenção dos espaços públicos. Disponível em: <http://www.aracaju.se.gov.br/index.php?act=leitura\&codigo $=45562>$. Acesso em: 30 maio 2011 .

ASSOCIAÇÃO BRASILEIRA DE NORMAS TÉCNICAS - ABNT. NBR 9050: Acessibilidade a edificações, mobiliário, espaços e equipamentos urbanos. Rio de Janeiro, 2004. 97 p.

BRASIL. MINISTÉRIO DAS CIDADES (SEMOB). Estatuto da mobilidade urbana: texto básico de fundamentação do anteprojeto de lei. Documento para discussão. Brasília: Ministério das Cidades, 2005. Mimeografado.

BRASIL. Lei no. 9.605, de 12 de fevereiro de 1998. Lei de Crimes Ambientais. Disponível em: <http://www.planalto.gov.br/ccivil_03/Leis/L9605.htm>. Acesso em: 19 abr. 2011.

BARGOS, D. C.; MATIAS, L. F. Áreas Verdes urbana: um estudo de revisão e proposta conceitual. Revista da Sociedade Brasileira de Arborização Urbana, Piracicaba - SP, v.6, n.3, p.172-188, 2011.

CAVAlCANTE, M. R. C. Avaliação de Qualidade Térmica de Praças em Maceió/Alagoas: Três Estudos de Caso. 2007. 168 f. Dissertação (Mestrado em Arquitetura e Urbanismo). Maceió: Universidade Federal de Alagoas.

DE ANGELIS, B. L. D.; CASTRO, R. M. de; DE ANGELIS NETO, G. Metodologia para levantamento, cadastramento, diagnóstico e avaliação de praças no Brasil. Revista Engenharia Civil: Londrina, n. 20, 2004.

GUZZO, P.; CARNEIRO, R. M. A.; JÚNIOR, H. O. Cadastro municipal de espaços livres urbanos de Ribeirão Preto (SP): acesso público, índices e base para novos instrumentos e mecanismos de gestão. Revista da Sociedade Brasileira de Arborização Urbana, Piracicaba, v.1, n.1, p.19-30 2006.

IBGE. IBGE Cidades. Disponível em: <http://www.ibge.gov.br/cidadesat/topwindow.htm?1>. Acesso em: 04 abr. 2011.

JESUS, S. C. de; BRAGA, R. Análise Espacial das Áreas Verdes Urbanas da Estância de Águas de São Pedro - SP. Caminhos da Geografia: Uberlândia, n. 18, v. 16, p. 207-224, out -2006 .

JULIÃO, D.; IKEMOTO, S. M. O Direito ao Lazer do Deficiente Visual em Áreas Naturais Públicas e Unidades de Conservação. Disponível em: http://www.ivtrj.net/sapis/2006/pdf/DanielleJuliao.pdf. Acesso em: 26 set. 2011. 
LAMAS, J. M. R. G. Morfologia Urbana e Desenho da Cidade. 3. ed. Porto: Fundação Calouste Gulbenkian para a Ciência e Tecnologia, 2004. 590 p.

LIMA, A. M. L. P.; CAVAlHEIRO, F.; NUCCI, J. C. SOUSA. M. A. de L. B.; FIALHO, N. de O.; DEL PICCHIA, P. C. D. Problemas de Utilização na Conceituação de Termos como Espaços Livres, Áreas Verdes e Correlatos. II Congresso Brasileiro de Arborização Urbana. São Luís, 18 a 24 de setembro de 1994. Anais... 1994.

MACHADO, C. S.; WAISMAN, J. Alteração na Acessibilidade a Pontos de Interesse Decorrentes da Implantação do Rodoanel Mário Covas na Região Metropolitana de São Paulo. Disponível em: <http://www.cbtu.gov.br/estudos/pesquisa/antp_15congr/pdf/DU196.pdf>. Acesso em: $01 \mathrm{dez} 2011$.

MASCARÓ, L.; MASCARÓ, J. J. Ambiência Urbana: Urban Environment. 3. ed. Porto Alegre: Masquatro, 2009. 199 p.

MONTELLI, C. C. C. Avaliação Estética e Uso de Três Praças em Pelotas/RS. 2008. 145 f. Dissertação (Mestrado em Planejamento Urbano e Regional). Porto Alegre: Universidade Federal do Rio Grande do Sul.

MOTA, M. A. R. Sílvio Romero: Dilemas e combates no Brasil da virada do século XX. Rio de Janeiro: FGV Editora, 2000. 120 p.

PRADO, G. da S. Batalhas da Memória Política em Sergipe: As comemorações das mortes de Fausto Cardoso e Olímpio Campos (1906-2006). 2009.172 f. Dissertação (Mestrado em História). Brasília: Universidade de Brasília.

ROBBA, F; MACEDO, S. Praças Brasileiras. São Paulo: EDUSP, 2003283 p.

SANTOS, R. F. dos. Planejamento Ambiental: Teoria e Prática. São Paulo: Oficina dos Textos, 2004. $184 \mathrm{p}$.

ROLNIK, R. O que é a cidade. São Paulo: Brasiliense, 1998. 212 p.

SCHANZER, H. W. Contribuições da Vegetação para o Conforto Ambiental no Campus Central da PUCRS. 2003. 162 p. Dissertação (Mestrado em Engenharia Civil). Porto Alegre: Universidade Federal do Rio Grande do Sul.

SEGAWA, H. Ao Amor do Público: Jardins no Brasil. São Paulo: Studio Nobel, FAPESP, 2005. $255 \mathrm{p}$. 
SILVA, C. R. F. da. Praças Públicas e Sustentabilidade da Cidade. 2010. 175 f. Dissertação (Mestrado em Desenvolvimento e Meio Ambiente). São Cristóvão: Universidade Federal de Sergipe.

SILVA FILHO, D. F.; PIZZETTA, P. U. C.; ALMEIDA, J. B. S. A. de; PIVETTA, K. F. L.; FERRAUDO, A. S. Banco de Dados Relacional Para Cadastro, Avaliação e Manejo da Arborização em Vias Públicas. Revista Árvore, v. 26, n. 5, p. 629-642, 2002.

SOUZA, A. L.; FERREIRA, R. A.; MELLO, A. A.; PLÁCIDO, D. R.; SANTOS, C. Z. A.; GRAÇA, D. A. S.; ALMEIDA JÚNIOR, P. P.; BARRETTO, S. S. B.; DANTAS, J. D. M.; PAULA, J. W. A.; SILVA, T. L.; GOMES, L. P. S. Diagnóstico quantitativo e qualitativo da arborização das praças de Aracaju, SE. Revista Árvore. UFV: Viçosa, v.35, n.6, p.12531263, 2011.

SOUZA, A. P. de. Análise de Qualidade Ambiental Urbana em Praças Públicas através da Percepção dos seus Usuários: O caso da Praça Dois de Julho - Campo Grande Salvador-Bahia. 2009. 142 f. Dissertação (Mestrado em Engenharia Ambiental). Salvador: Escola Politécnica, Universidade Federal da Bahia. 